\title{
Relaciones y perspectivas de la entrada de Costa Rica a la Alianza del Pacífico
}

\author{
Relation and perspectives of the Costa Rica's entry to the Pacific Alliance
}

\author{
Raúl Fonseca Hernández ${ }^{1}$ \\ Jorge Rivera Hernández ${ }^{2}$ \\ Sharon Recinos Carvajal ${ }^{3}$
}

Fecha de recepción: 1-11-2019

Fecha de aprobación: 9-03-2019

\begin{abstract}
Resumen
Desde el 2016, Costa Rica ha aplicado una moratoria a la decisión del ingreso a la Alianza del Pacífico (AP). El objetivo de la presente investigación es analizar, por medio de indicadores y datos económicos y comerciales, las posibles oportunidades y riesgos que podrían tener el país con la entrada a la AP. Para lo cual, se establecerá un índice de importancia económica y comercial, conformada por variables que determinan el intercambio comercial (importaciones y exportaciones), la inversión extranjera directa, así como el ingreso de turistas que se movilizan entre Costa Rica y los países miembros de la Alianza. La investigación logra determinar que existirían beneficios con la entrada de Costa Rica a la AP, a pesar de que el país ya cuenta con tratados comerciales bilaterales con la mayoría de las naciones que integran la AP, y que existen sectores sociales importantes que poseen dudas razonables sobre los efectos que pueda tener para el país el ingreso a la AP.

Palabras claves: Alianza del Pacífico (AP), índice de importancia económica, intercambio comercial, inversión extranjera directa (IED) y turismo.
\end{abstract}

\begin{abstract}
Since 2016, Costa Rica has applied a moratorium on the decision to join the Pacific Alliance (PA). The objective of the present investigation is to analyze by means of economic and commercial indicators and data the possible opportunities and risks that the country could have with the entrance to the PA. For which an economic and commercial importance index will be established, consisting of variables that determine the commercial exchange (imports and exports), direct foreign investment, as well as the entrance of tourists that are mobilized between Costa Rica and the member countries of the alliance. The research is able to determine that there would be benefits with the entry of Costa Rica to the PA, despite the fact that the country already has bilateral trade agreements with most of the nations that make up the PA, and that there are important social sectors that have reasonable doubts about the effects that the entry to the PA may have for the country.

Keywords: Pacific Alliance (PA), Index of Economic Importance, Trade Exchange, Foreign Direct Investment and Tourism.

1 Economista. Doctorando del Programa de Estudios sobre Desarrollo del Instituto HEGOA, Universidad del País Vasco, España, Académico de la Escuela de Relaciones Internacionales de la Universidad Nacional y de la Sede de Occidente de la Universidad de Costa Rica. Correo: raul. fonseca.hernandez@una.ac.cr.

2 Relacionista Internacional. Académico de la Escuela de Relaciones Internacionales de la Universidad Nacional, Costa Rica. Correo: jorge. rivera.hernandez@una.cr

3 Bachiller en Economía. Asistente de la Escuela de Relaciones Internacionales de la Universidad Nacional, Costa Rica. Correo: sharon. recinos.carvajal@est.una.ac.cr
\end{abstract}




\section{Introducción}

Los sistemas multilaterales de países en las áreas de comercio, economía y cooperación son sistemas que mejoran la competitividad y mejoran las perspectivas de desarrollo de los países que lo integran. En la época de la globalización no es posible negar la importancia de la apertura e intercambio comercial entre naciones. Sin embargo, la misma teoría económica de crítica al desarrollo ortodoxo advierte de los riesgos que puede tener para países, sectores y territorios que no estén preparados para afrontar la competencia. Especialmente prevé la necesidad del apoyo estatal y la planificación empresarial para que los sectores que podrían verse más perjudicados con dicha apertura comercial puedan mejorar sus condiciones y enfrentar los nuevos retos.

Parte de este sistema mundial es la AP, la cual es una Alianza multilateral que propicia una integración entre América Latina y el continente asiático. Fue creado en el 2011, mediante la declaración de Lima, como una plataforma de profundización comercial, política y económica integrada por México, Chile, Colombia y Perú. Cuenta, también, con 59 Estados Observadores en el 2020. Para adherirse como Estado Parte, los países interesados deben tener vigente un acuerdo de libre comercio con cada una de las partes que integran esta iniciativa.

Este artículo busca analizar datos macroeconómicos actuales, que permitan dimensionar el intercambio comercial y turístico poseídos por los países miembros de la AP con Costa Rica, para proponer un índice de importancia económica, que admita visualizar las posibles oportunidades que podría potenciar Costa Rica con el ingreso del país en la AP, tanto a nivel grupal como individual. Se busca contestar las siguientes preguntas de investigación: ¿Cuál es el comportamiento y evolución de las principales variables macroeconómicas que permiten establecer una relación entre Costa Rica y los países miembros de la AP?, y ¿Cuáles países de la AP y en qué áreas podrían representar una oportunidad para Costa Rica?

El artículo se estructura en cinco secciones: el primero, presenta la metodología que se utilizó en la investigación.
El segundo acápite, realiza un análisis referencial sobre la creación de la AP, así como un análisis general de actores que podrían estar a favor o en contra de la integración. La tercera sección, un análisis descriptivo de la evolución de variables en estudio: apertura comercial, turismo e inversión extranjera directa, tanto para Costa Rica como para los países miembros de la AP. El cuarto apartado, presenta los resultados de la construcción y análisis de un índice de importancia económica y comercial que muestra de forma ponderada, la evolución de la importancia de los países miembros de AP para Costa Rica, desde el 2011 al 2018. Por último, se presentan las reflexiones finales sobre las posibles repercusiones económicas y comerciales que podrían tener la entrada de Costa Rica a la AP.

\section{Marco Metodológico}

La investigación es de tipo cuantitativo, al analizar descriptiva e inferencialmente datos que reflejan el intercambio comercial y económico entre los países miembros de la AP y Costa Rica. El análisis se centra en las siguientes variables: comercio internacional total, explicado por las importaciones y exportaciones totales, principales productos de importación y exportación, visitación turística, así como atracción de inversión extranjera directa. Los datos disponibles son para el periodo comprendido entre el 2011 hasta el 2018.

Para el análisis de los resultados se utilizan dos técnicas principales. En primera instancia, se realiza un análisis descriptivo y tendencial de las variables en estudio. Asimismo, se construye un índice para determinar la importancia relativa ponderada del intercambio comercial que mantiene Costa Rica con los países miembros de la AP.

Para la elaboración del índice, se utilizan las variables en análisis (comercio internacional total, inversión extranjera directa y turismo). Para el tratamiento de los datos, se sigue la propuesta metodológica desarrollada por Fonseca (2012), la cual realiza una estandarización de los datos para eliminar las diferentes unidades de medida y hacer comparables los indicadores analizados, manteniendo la magnitud de valor de estos en un rango de 0 a 1 . Posteriormente, se ponderan por cada variable con igual peso, 33, 3\% para cada componente, dado lo 
focalizado del análisis en las tres variables que explican la apertura comercial de los países. Los indicadores utilizados y la ponderación propuesta, fue validada por otros estudios (Fonseca y López, 2018; Fonseca y López 2015), así como un panel de ocho expertos nacionales y tres internacionales, quienes validaron mediante una encuesta electrónica aplicada en el mes de enero del 2019, las variables a utilizar y la respectiva ponderación.

La generación de un índice tiene aspectos positivos y elementos a valorar. Entre los positivos se destacan la posibilidad de poder integrar diversos indicadores que tengan unidades de medida disímiles y hacerlos comparables mediante la estandarización, asimismo, permite trabajar con datos en los cuales no existe una serie de tiempo amplia, o que se generan con temporalidades discontinuas, de este modo, permite ponderar variables con diferente peso o importancia relativa, y mostrar variables con alguna lógica de jerarquización. Dentro de los elementos a valorar que podría convertirse en aspectos negativos se encuentran los criterios utilizados para la ponderación de las variables o indicadores, el hecho de que, si no se garantiza la continuidad en la recolección de datos, el índice permitirá mostrar una realidad compleja en un momento en el tiempo, pero podría no poder compararse con otros en lapsos diferentes.

\section{Marco referencial}

La Alianza del Pacífico fue creada en 2011, actualmente está conformada por cuatro países de Latinoamérica: México, Chile, Colombia y Perú. Su creación tiene por objetivo mejorar la integración regional, "generar crecimiento, desarrollo y competitividad de las economías con el fin de mirar en forma conjunta hacia el Asia-Pacífico, región que se fortalece como un centro fundamental de la economía mundial de este siglo" (López y Muñoz, 2012, p. 1). Además, cuenta con Estados Asociados, que en 2020 supone un vínculo, en negociación, con Australia, Canadá, Nueva Zelanda y Singapur.

Según cifras de la OCDE (2019), la AP como bloque, representa la octava potencia económica a nivel mundial, alberga un mercado de 228 millones de personas y un crecimiento del PIB per cápita total de 3.65\%, cifras del
Banco Mundial al año 2017. Además, el Fondo Monetario Internacional (FMI) justifica que el Producto Interno Bruto (PIB) de los países de la AP ascendió a 3,8 billones USD en el 2016, por lo que representa el 40,9\% del PIB de América Latina y el Caribe y un 3,2\% del producto interno bruto mundial.

En estos ocho años en el marco de negociaciones el bloque de la Alianza ha logrado importantes aportes, entre ellos se encuentran: la circulación del 92\% de bienes y servicios con cero aranceles entre los países miembros, el 8\% restante se encuentra en proceso de desgravación como parte del Protocolo Adicional, firmado en 2014, para un bloque comercial de mayor integración. Otro aporte consiste en el mejoramiento de medidas sanitarias para los productos en circulación, cooperación aduanera más robusta, facilidades en algunos servicios como transacciones financieras y comercio electrónico, mayor movilidad estudiantil y académica, que contribuye con la formación de capital humano de alto nivel, ligado al otorgamiento de 2240 becas en total de la Plataforma Académica y Estudiantil (Del Pacífico, 2019).

Costa Rica fue aceptada como Estado Observador en el año 2012, durante la administración Chinchilla, considerado como candidato para ser estado parte de la AP en algún momento no definido. Sin embargo, en 2016 durante el gobierno del Presidente Luis Guillermo Solís, se pone un alto al proceso de ingreso, principalmente por resistencia de diversos sectores sociales. Según Cascante y Fonseca (2017) existen sectores a favor y en contra del ingreso del país a la AP. Entre los sectores que adversan la iniciativa, se encuentran los productivos, especialmente el agrícola, quienes aducen que los menores costos relativos de producción con los que cuentan los países actualmente miembros de la AP, será perjudicial para los productores nacionales. Asimismo, el sector sindical, históricamente ha estado opuesto al modelo de desarrollo basado en la apertura comercial y son fuertes abanderados en la defensa de los agricultores y productores nacionales.

Así pues, los autores mencionan que el sector empresario, encabezado por el Consejo Empresarial de la Alianza del Pacífico (organización que agrupa diversas cámaras empresariales y zonas francas, creado en 2012) y ciertas 
agrupaciones políticas como el Movimiento Libertario, una parte de Liberación Nacional, entre otros, son fuertes aliados de la inclusión de Costa Rica a la AP. Ahora bien, los beneficios plausibles de la integración del país a la Alianza del Pacífico observados son: aumentar el intercambio de bienes y servicios, así como la mejora en la competitividad de los países miembro, atracción de turismo e inversiones, acceso a nuevos mercados, además de la mejora en la formación educativa (Cascante y Fonseca, 2017). Es importante mencionar, que mucho de los argumentos utilizados por estos actores son coincidentes con los argumentos teóricos que respaldan la apertura comercial, siendo interesante analizar en futuros estudios, el impacto verdadero en diversos sectores de la inclusión de Costa Rica a la AP, en los términos en los cuales está planteado en la actualidad.

Actualmente, Costa Rica cuenta con Tratados de Libre Comercio (TLC) con cada uno estos países. Desde 1995 se tiene el TLC con México, a partir del 2002 Costa Rica y Chile establecieron un TLC que les ha permitido beneficiarse de condiciones arancelarias, en el 2014 entró en vigor el Tratado de Libre Comercio Costa Rica - Perú y en el 2014 se firma el TLC con Colombia. Igualmente se plantea la posible mejora comercial con los países del Asia, actualmente se recibe flujos de capital proveniente de China, Corea, Japón, Taiwán, el cual al año 2018 se recibió un total de \$ US134.6 millones. En el caso de China, desde el 2011 se firmó un TLC y desde entonces se han exportado productos como circuitos integrados y microestructuras electrónicas, partes para emisores y receptores de TV, radio y similares, madera en bruto, materiales eléctricos, otros dispositivos y circuitos electrónicos, semiconductores por un monto de \$ US162 millones, según datos de COMEX, para el 2018.

Por otro lado, es importante plantearse los aportes que generaría la Alianza al país, por lo que la situación de Latinoamérica es relevante en este análisis. Durante los últimos años, se han logrado grandes avances en términos de prosperidad que han experimentado los países del continente. No obstante, según CEPAL (2019), la proporción de personas en situación de pobreza extrema continuó creciendo, y sigue una tendencia creciente desde el 2015, especialmente los países que conforman la AP siguen presentando altos problemas de pobreza, desempleo, baja competitividad y poco crecimiento comparado con los países del Asia, que en la actualidad poseen un mercado de gran magnitud y de creciente poder adquisitivo.

Algunas de las razones, por las cuales se siguen presentando estos problemas y que explican el atraso económico en comparación a las naciones asiáticas, corresponden a la escasa apertura comercial, baja productividad, poco valor agregado, rezagos en el sector tecnológico e innovación, que se sigue presentando en los aparatos productivos. Razón por la que, según Arévalo (2014), la Alianza del Pacífico ampliará las oportunidades comerciales y financieras de los países del acuerdo, con países del Asia que poseen gran dinamismo en el crecimiento económico como China, Japón, India y Corea del Sur.

Esta Alianza pretende según Arévalo (2014, p.167):

- Fomentar el crecimiento económico para enfrentar el desempleo regional.

- Mejorar la integración comercial y financiera y el desarrollo tecnológico.

- Agilizar la integración con Asia para aumentar el volumen de exportación.

- Atraer inversión extranjera y turismo en mayores volúmenes.

- Diversificar las relaciones económicas y políticas con los países del Asia Pacífico.

Siendo así, la AP promete ir más allá de un tratado de libre comercio donde se amplían los mercados de bienes y servicios de los participantes o se negocia simplemente la eliminación o la baja de aranceles para los bienes entre las partes. Por lo que, para Costa Rica, formar parte de un bloque de integración económica y comercial que sea el más grande de América Latina, y que supere al Mercosur, no deja de ser una propuesta interesante en temas económicos. 


\section{Resultados}

Una vez expuestos los fundamentos teóricos del análisis, en esta sección se exponen los resultados obtenidos producto de una recopilación de fuentes de información de carácter secundario.

La primera parte del análisis está compuesta por un análisis descriptivo del intercambio comercial entre los países que conforman la AP y de la relación de intercambio que posee Costa Rica con el bloque. La segunda parte se propone el índice de importancia económica para determinar la importancia relativa ponderada del intercambio comercial que mantiene Costa Rica con los países miembros de la AP.

\subsection{Relaciones de intercambio comercial entre los países miembros de la AP}

En el gráfico 1 se puede observar dos momentos del intercambio comercial de los cuatro países miembros a la AP, representado por el total de importaciones y exportaciones reales que realizan con cada uno de los países miembros. Un primer momento sucede en el periodo que comprende 2005-2010 cuando aún no existía la iniciativa de integración regional y, un segundo momento, cuando forman parte de esta iniciativa y empieza el camino hacia una libre circulación de bienes, servicios, capital y personas, el periodo 2011-2018.

\section{Gráfico 1. Intercambio Comercial entre los países miembros de la AP (2005-2018)}

\section{Millones de dólares}

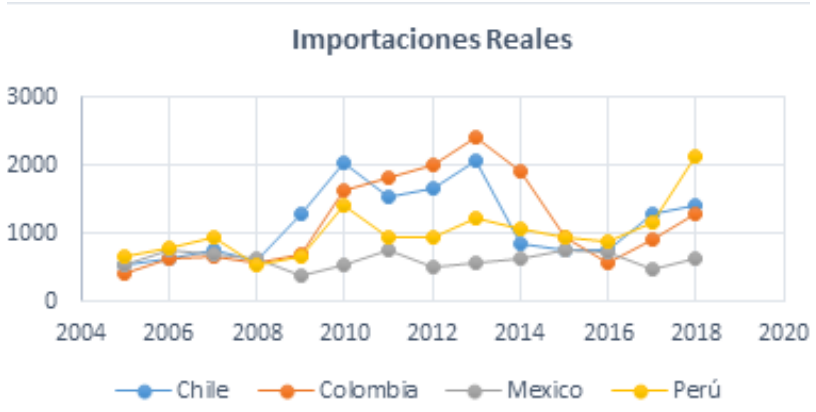

Exportaciones Reales

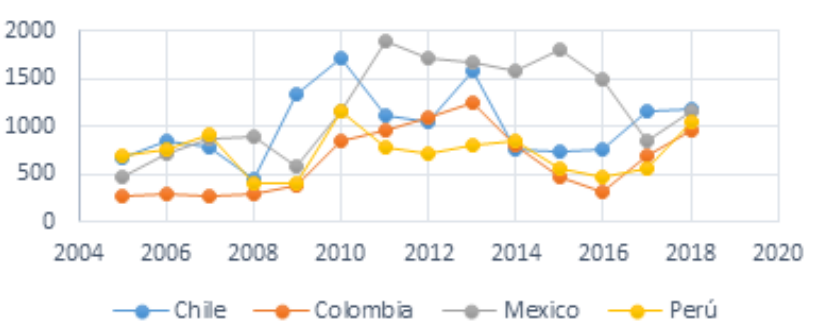

Fuente: Elaboración propia, con base en: Banco de la Reserva del Perú (2019), Banco de la República- Colombia (2019), Banxico (2019), Banco Central de Chile (2019), Departamento Administrativo Nacional de Estadística (2019), Dirección Nacional de Aduanas de Chile (2019), Comisión de Promoción del Perú para la Exportación y el Turismo (2019), Sistema de Información Económica de México (2019), Passport (2019).

En lo que respecta al intercambio comercial los países de la AP han experimentado un incremento en el volumen de sus exportaciones e importaciones desde el 2011, siendo así al año 2018 exportaron US \$616,550 millones superando lo exportado por los países del Mercosur US $\$ 40,281$, donde forman parte Brasil, Argentina, Uruguay y Paraguay. Adicionalmente, sus importaciones alcanzaron los US\$625,442 millones superando los US\$ 34,660 millones importados por el Mercosur. Según Del Pacífico (2019), los países de la Alianza recibieron 54 millones de turistas en el último año y una captación de Inversión Extranjera Directa del 38\% del total que llegó a América Latina en el 2017. Por lo que para México, Chile, Colombia y Perú esta integración regional se ha reflejado en un mayor crecimiento, desarrollo y competitividad de sus economías.

\section{a. Relaciones de intercambio comercial entre Costa Rica y los países miembros de la AP}

Actualmente, Costa Rica como estado observador de la AP, mantiene tratados de libre comercio con cada uno de los cuatro países miembros. El total de exportaciones destinadas a los países de la AP alcanzó los US\$ 394.43 millones en el 2018, representando el 3.50\% de las exportaciones totales del país, en el caso de las importaciones alcanzó el 10.99\% provenientes de la AP. 
Lo que respecta a la magnitud de intercambio que realizan los países de la AP y Costa Rica, según los datos analizados, Chile, Colombia, Perú y Costa Rica importan más de México, que de cualquier otro país de la AP. Así mismo, México importa actualmente más de Costa Rica que de los miembros de la Alianza. En el caso de las exportaciones de México, Perú y Colombia, sus productos se dirigen en mayor volumen a Chile que a cualquier otro país de la AP; en el caso de Chile, sus exportaciones tienen mayor destino a Perú y en el caso de Costa Rica, a México.

Costa Rica es un país que ha logrado diversificar su oferta exportable al sumarle a los productos tradicionales de exportación como lo son el café, el banano y la piña, nuevos bienes como los dispositivos médicos, microchips y también algunos servicios por ejemplo las telecomunicaciones, shared-services y el turismo, que cada día adquieren mayor protagonismo. Los países miembros de la Alianza como México se caracterizan por la exportación de vehículos, aceites crudos de petróleo, pantallas planas, mientras lo que respecta a Colombia se encuentra el café, carbón, petróleo y derivados, por otra parte, Chile exporta minerales de cobre y oro, productos químicos provenientes de vegetaciones como el eucalipto y coníferas y Perú: mineral de cobre, oro y petróleo.

Los países que integran la Alianza del Pacífico constituyen uno de los principales bloques productores de recursos minerales en el mundo. Según Ulloa (2017) sobre el sector minero de los países de la AP es uno de los más importantes para América Latina. En conjunto, son el primer productor mundial de cobre (con el $43 \%$ de participación en el mercado y el $47 \%$ de las reservas conocidas), y de plata (con el $41 \%$ de la producción y el mismo porcentaje de reservas conocidas). También, son relevantes sus depósitos de molibdeno, oro y zinc, que ubican al conglomerado como el segundo productor del mundo después de China (con el 37\% del molibdeno, el 17\% del zinc, y el 12.5\% del oro). La Alianza del Pacífico produce, además, hierro, níquel y litio, entre otros minerales, Ulloa (2017).

Este análisis coloca al sector minero como un factor determinante y promotor de desarrollo económico sostenido, para estos países miembros de la AP. En consecuencia el potencial desarrollo sectorial de estos países, podría generar beneficios a Costa Rica mediante el intercambio comercial.

La tabla 1 muestra los productos que actualmente se exporta y se importa de los países miembros de la AP, a precios corrientes en millones de dólares (USD).

\section{Tabla 1. Principales tres productos de intercambio} comercial de Costa Rica con los países de la AP.

\begin{tabular}{|c|c|c|c|c|}
\hline País & $\begin{array}{l}\text { Productos } \\
\text { importados }\end{array}$ & $\begin{array}{l}\text { Millones } \\
\text { USD\$ }\end{array}$ & $\begin{array}{l}\text { Productos } \\
\text { exportados }\end{array}$ & $\begin{array}{l}\text { Millones } \\
\text { de USD\$ }\end{array}$ \\
\hline \multirow{4}{*}{ Colombia } & Medicamentos & 15.83 & Plomo en bruto & 11.87 \\
\hline & Polipropileno & 8.61 & $\begin{array}{l}\text { Dispositivos } \\
\text { médicos }\end{array}$ & 7.68 \\
\hline & $\begin{array}{l}\text { Perfumes } \\
\text { y aguas de } \\
\text { tocador }\end{array}$ & 8.51 & Llantas & 4.26 \\
\hline & $\begin{array}{l}\text { Alambre de } \\
\text { cobre }\end{array}$ & 69.52 & $\begin{array}{l}\text { Preparaciones } \\
\text { alimenticias }\end{array}$ & 6.28 \\
\hline \multirow[t]{3}{*}{ Chile } & $\begin{array}{l}\text { Madera } \\
\text { aserrada o } \\
\text { devastada de } \\
\text { pino }\end{array}$ & 39.90 & $\begin{array}{l}\text { Cantos, } \\
\text { grava, piedras } \\
\text { machacadas }\end{array}$ & 5.12 \\
\hline & $\begin{array}{l}\text { Carne de cerdo } \\
\text { congelada }\end{array}$ & 20.89 & $\begin{array}{l}\text { Frutas } \\
\text { congeladas }\end{array}$ & 3.16 \\
\hline & $\begin{array}{l}\text { Vehículos para } \\
\text { el transporte } \\
\text { de personas }\end{array}$ & 56.81 & Aceite de palma & 91.53 \\
\hline \multirow[t]{2}{*}{ México } & $\begin{array}{l}\text { Vehículos } \\
\text { pesados }\end{array}$ & 48.05 & $\begin{array}{l}\text { Circuitos } \\
\text { integrados y } \\
\text { microestructuras } \\
\text { electrónicas }\end{array}$ & 25.80 \\
\hline & Medicamentos & 48.00 & $\begin{array}{l}\text { Preparaciones } \\
\text { alimenticias }\end{array}$ & 23.57 \\
\hline \multirow[b]{3}{*}{ Perú } & Aguacates & 6.67 & $\begin{array}{l}\text { Las demás } \\
\text { manufacturas de } \\
\text { hierro o acero }\end{array}$ & 6.61 \\
\hline & Uvas frescas & 5.60 & Medicamentos & 2.39 \\
\hline & $\begin{array}{l}\text { Láminas y } \\
\text { placas de } \\
\text { plástico, con } \\
\text { polímeros de } \\
\text { etileno }\end{array}$ & 3.84 & $\begin{array}{l}\text { Tapones y tapas } \\
\text { de metal común }\end{array}$ & 1.99 \\
\hline Total & & 332.23 & & 190 \\
\hline
\end{tabular}

Fuente: Elaboración propia, con datos recopilados de Comercio Exterior de Costa Rica (2019). 
En la tabla anterior se puede apreciar que Colombia, es un importador relevante de los principales productos de exportación de Costa Rica, como lo son los dispositivos médicos. Mientras que desde Costa Rica se exportan otros productos como plomo, llantas, alimentos preparados, medicamentos, entre otros. Aunado a lo anterior, según Comex (2019), en noviembre del 2017, mediante la realización de la segunda reunión de la Comisión de Libre Comercio, se toman una serie de decisiones que concluye con mejoras en acceso a mercados para productos que se comercializan entre Costa Rica y Colombia, entre ellos se encuentran:

(...) neumáticos, loza sanitaria y ciertos productos textiles. De igual forma, se concretó la modificación en las reglas específicas de interés de ambas partes para dispositivos médicos y preparaciones tensoactivas líquidas o en crema para el lavado de la piel. (p.1)

Actualmente, según el Banxico, las compras de México al exterior representan el 37,22\% de su Producto Interno Bruto, lo que lo coloca en un ranking de los países con mayor volumen de importación. Entre sus principales importaciones se destaca los circuitos integrados y microestructuras electrónicas. En el 2017, las compras de este producto al país sumaron un total de US\$ 25.80 millones colocando a México como uno de los mejores compradores de circuitos integrados de Costa Rica. Otro dato importante de resaltar es que, además, las exportaciones anuales del país dirigidas a México experimentaron un crecimiento interanual del $4 \%$ del 2017 al 2018, un crecimiento bastante elevado.

En el caso de las exportaciones realizadas a Chile, estas han experimentado un crecimiento interanual del 4.35\%, donde las preparaciones alimenticias, cantos, grava y piedras machacadas se encuentran entre los principales productos exportables. Asimismo, en el 2018 se importó un total de US\$ 279.29 millones, donde los productos que más se importaron fueron alambre de cobre, madera aserrada, carne de cerdo congelada, medicamentos y vinos.
Unido a lo anterior, Perú es el país de la AP con el que se tiene menor intercambio comercial, medicamentos y artículos de manufactura son algunos de los productos que se exportan. Del total de importaciones que realiza Costa Rica desde los países de la AP, Perú representa el $3.62 \%$, y entre las principales compras destacan frutas como (uvas, aguacates), productos fabricados a base de plástico y productos de panadería.

\subsection{La Inversión Extranjera Directa entre Costa Rica y los países miembros de la AP}

La atracción de flujos de inversión extranjera directa para ampliar las posibilidades de desarrollo es otra de las variables en análisis, ya que la IED impacta positivamente en la capacidad productiva del país receptor. Según Obeid (2015) esta se encarga de alimentar a los países receptores con la entrada de capitales, conocimientos tecnológicos, desarrollo del capital humano y la capacidad de gestión necesaria para el desarrollo económico sostenible.

Respecto a la Inversión Extrajera Directa de los países de la Alianza, Peñaranda (2016) afirma que:

Los países miembros de la Alianza del Pacífico (AP) captaron como flujo de IED durante el 2016 un total de US $\$ 58.845$ millones, lo que representa el 3,3\% del PBI del bloque económico y una caída de 20,1\% respecto al 2015. Entre los países que conforman la AP, México concentra el 45,4\% de la IED, seguido en importancia por Colombia (23,1\%), Chile (19,8\%) y Perú (11,7\%) (p.2).

Según cifras del Banco Central de Costa Rica, para Costa Rica, el porcentaje de inversión extranjera directa total proveniente de los países de la AP para el 2018, fue de un 7.53\% del total. Sin embargo, esta registró una caída del $43.55 \%$ durante el 2018, con respecto al 2017, con una captación de flujo de \$US 160.80 millones, siendo el monto más bajo registrado en los últimos 8 años.

El siguiente gráfico presenta la tendencia de la IED de Costa Rica según país de origen, en el periodo que comprende 2011- 2018, con el monto en millones de dólares. 


\section{Gráfico 2. Inversión Extranjera Directa proveniente de los países de la Alianza del Pacífico}

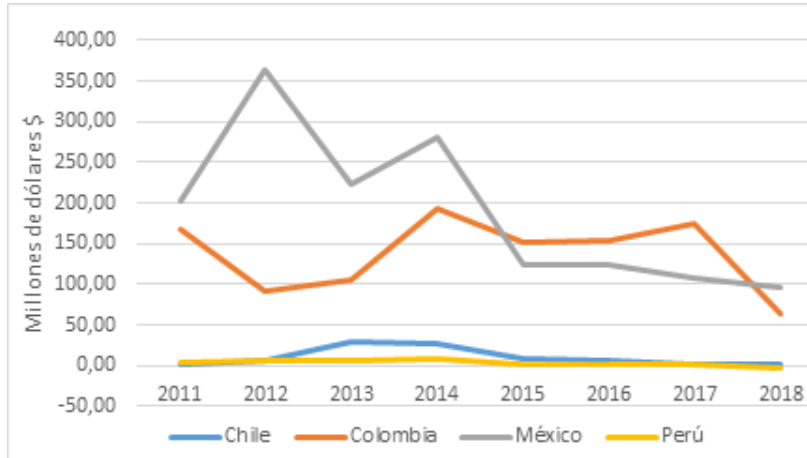

Fuente: Elaboración propia con datos tomados del Banco Central de Costa Rica (2019).

En el gráfico 2 se muestra como los flujos de inversión provenientes de los países de la Alianza, alcanzan cifras elevadas como lo es la captación de capital proveniente de México, en segundo lugar, la proveniente de Colombia y en menor medida la proveniente de Chile y Perú. En el caso de la IED proveniente de Perú, según Comex (2019), estas inversiones van dirigidas principalmente al sector manufacturero. Sin embargo, como se menciona anteriormente, es visible una caída tendencial en los últimos años de la IED proveniente de estos países.

Según Peñaranda (2016), para estos resultados, en gran parte la OMC justifica que dado "el menor crecimiento económico sobre todo en la zona del euro, la debilidad de la inversión a nivel mundial, la reducción del comercio de China y el estancamiento en la expansión de las cadenas globales de valor, explican la evolución del comercio mundial en los últimos años" (p.2) por lo que se ve reflejado en caídas en los términos de intercambio.

\subsection{El turismo entre Costa Rica y los países miembros de la AP}

En el sector turístico cabe señalar la importancia que representa este sector para el país, dado la generación de divisas, atracción de inversiones, estimulación de empleo y generación de riqueza, que este implica para los países receptores.
En vistas de la adhesión del país a la Alianza del Pacífico se plantean la eliminación de las visas a los Estados miembros, por lo que podría generar un aumento del flujo de turistas latinoamericanos al país, lo cual no representan el mercado tradicional actualmente, ya que, según el Instituto Costarricense de Turismo (ICT), la mayor parte de turistas que ingresan al país son los provenientes de Norteamérica y Europa, alcanzando al 2018 una cifra de 1.580 .991 y 480.102 personas respectivamente.

En el gráfico 3, se consideran la llegada de turistas de los países miembros de la AP, todas las vías, desde el año 2011 al año 2018.

\section{Gráfico 3. Visitación turística de los países de la Alianza del Pacífico a Costa Rica}

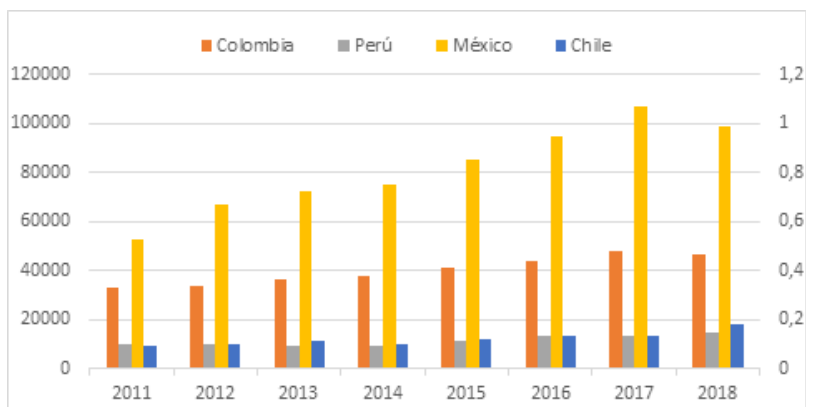

Fuente: elaboración propia con datos recopilados del Instituto Costarricense de Turismo (2019).

El aporte turístico de los países de la AP a Costa Rica oscila entre el $4.79 \%$ y $5.93 \%$ del total de turistas que se reciben en el país, alcanzando el ingreso total de 178 803 personas en el año 2018. Esto es observable en el continuo crecimiento que ha presentado las llegadas internacionales al país, mostrando este efecto en un crecimiento del 10,28\% en el 2017 con respecto al 2016. La distribución del flujo turístico del total de turistas de los países integrantes de la AP es a favor de México con un 55\%, seguido por Colombia con un $26 \%$ y finalmente Chile y Perú con un $10 \%$ y 8\%, respectivamente. 
México es el país que registra el mayor flujo de turistas en el país. Al año 2018, se registró una entrada de 98 918 mexicanos, por consecuente este país constituye un importante emisor de turistas a Costa Rica. Sin embargo, para este mismo año se presentó una disminución de $7.4 \%$ con respecto a los 106.783 ciudadanos mexicanos que ingresaron al país en el 2017, no obstante, el ICT mediante su estudio de mejores prospectos identifica aquellos turistas que poseen interés en visitar Costa Rica en algún momento en el futuro. Como resultado del estudio mejores prospectos, el ICT (2019) afirma que más turistas mexicanos tienen interés en visitar Costa Rica, pues "para este 2019 un total de 508.000 ciudadanos de ese país están interesados”, frente a los 450.000 que se identificaron en el informe del 2016.

\section{4. Índice de importancia económica para Costa Rica de los países miembros de la AP}

La creación del índice de importancia económica, para Costa Rica de los países miembros de la AP, permite ampliar el análisis en dos vías principales: inicialmente es posible determinar la evolución histórica en la importancia comercial de los países de la Alianza con respecto a Costa Rica. Asimismo, permite observar de forma gráfica las variables por país miembro, que Costa Rica podría fortalecer o generar estrategias para mejorar su aprovechamiento.

Por consiguiente, las cuatro variables importantes por considerar para la construcción del índice serán las exportaciones, importaciones, la inversión extranjera directa y el turismo, dado el enfoque teórico que la Alianza del Pacífico plantea. Luego de una serie de cálculos se muestra en la tabla 2 los resultados del índice en el tiempo.

Tabla 2. Resultados del índice de importancia económica para Costa Rica de los países miembros de la AP. 2011-2018

\begin{tabular}{|l|l|l|l|l|l|l|l|l|}
\hline & 2011 & 2012 & 2013 & 2014 & 2015 & 2016 & 2017 & 2018 \\
\hline Chile & $4 \%$ & $4 \%$ & $9 \%$ & $8 \%$ & $6 \%$ & $6 \%$ & $4 \%$ & $7 \%$ \\
\hline Colombia & $55 \%$ & $28 \%$ & $38 \%$ & $45 \%$ & $55 \%$ & $53 \%$ & $52 \%$ & $41 \%$ \\
\hline México & $100 \%$ & $100 \%$ & $100 \%$ & $100 \%$ & $94 \%$ & $93 \%$ & $87 \%$ & $100 \%$ \\
\hline Perú & $1 \%$ & $0 \%$ & $0 \%$ & $0 \%$ & $0 \%$ & $0 \%$ & $0 \%$ & $0 \%$ \\
\hline
\end{tabular}

Fuente: Elaboración propia, con base en: Banco de la Reserva del Perú (2019), Banco de la República- Colombia (2019), Banxico (2019), Banco Central de Chile (2019), Instituto Costarricense de Turismo (2019), Banco Central de Costa Rica (2019), Centro de Información Turística de Colombia (2019), Departamento Administrativo Nacional de Estadística (2019), Dirección Nacional de Aduanas de Chile (2019), Comisión de Promoción del Perú para la Exportación y el Turismo (2019), Sistema de Información Económica de México (2019). 
Cada indicador posee una ponderación diferenciada dentro de las cuatro variables establecidas, mostrándose en la tabla anterior la ponderación total por país a lo largo del periodo de estudio (2011-2018).

Figura 1. Determinantes de la importancia económica para Costa Rica de los países miembros de la Alianza del Pacífico.

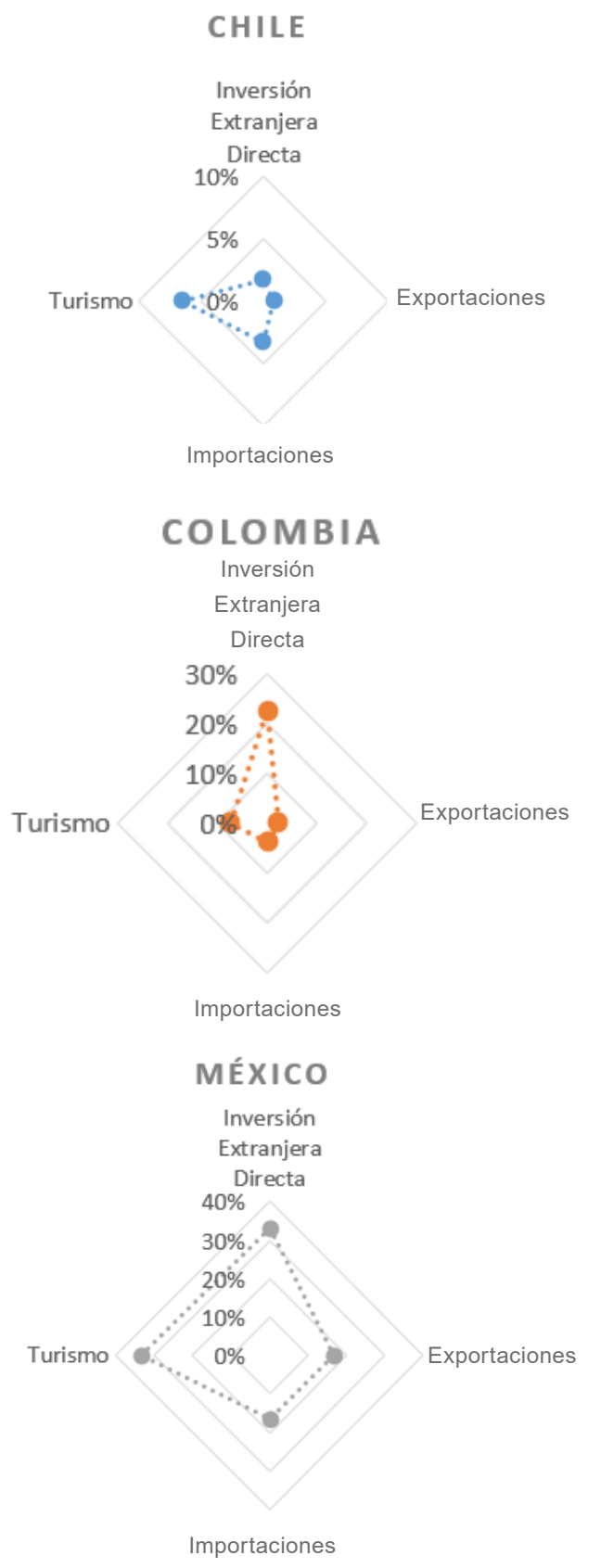

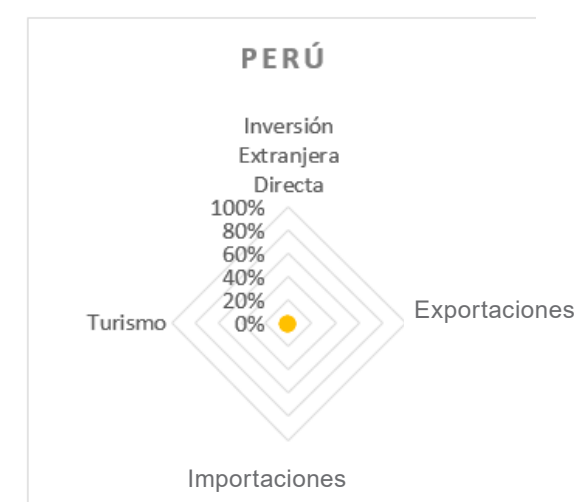

Fuente: Elaboración propia, con base en: Banco de la Reserva del Perú (2019), Banco de la República- Colombia (2019), Banxico (2019), Banco Central de Chile (2019), Instituto Costarricense de Turismo (2019), Banco Central de Costa Rica (2019), Centro de Información Turística de Colombia (2019), Departamento Administrativo Nacional de Estadística (2019), Dirección Nacional de Aduanas de Chile (2019), Comisión de Promoción del Perú para la Exportación y el Turismo (2019), Sistema de Información Económica de México (2019).

La figura 1 presenta las variables que determinan la importancia económica para Costa Rica de los países de la AP. En consecuencia, si el país desea aumentar la relación comercial con México, Chile, Colombia y Perú, mediante la incorporación a la Alianza, deberá focalizar acciones en las variables descritas. De este modo, si los países miembros de como bloque desean evaluar opciones para establecer relaciones comerciales con otras naciones, deberá considerar las variables presentadas.

En primer lugar, la variable inversión extranjera directa es el elemento que determina en mayor medida la importancia económica para el país, por parte de los países miembros de la AP. Los flujos de inversión provenientes de México y Colombia son los más altos y constantes con respecto a los demás países de la AP. En primer lugar, México tiene el nivel más alto de importancia económica dado que es el segundo país en importancia como origen de Inversión Extranjera Directa (IED) del país, debido a que aporta 5.17\% del total de IED, solo superado por Estados Unidos que tradicionalmente ha sido el mayor inversor en Costa Rica por décadas con un 57.11\% del total de IED. 
Por el contrario, Perú es el que aporta en menor cantidad a esta variable, asociado a la poca colocación de capitales a largo plazo que realiza este en el mundo; sin embargo, según el último informe de la Comisión Económica para América Latina y el Caribe, Perú se colocó en el cuarto lugar en América del Sur como país receptor de inversión extranjera directa, durante el año 2017.

En segundo lugar, la variable intercambio comercial está conformada por el intercambio de bienes y servicios que se efectúa entre los habitantes de los países miembros de la Alianza y Costa Rica. Destacando su importancia dado que permite acceder al país a una gama de productos que no se producen en él mismo por la escasa dotación de recursos productivos como es el caso de los minerales. En el caso de los países analizados, México tiene el mejor resultado en este componente y Perú se ubica en la posición más baja, por lo tanto es interesante destacar el aumento tendencial de las cifras de intercambio que mantiene el país con México.

En tercer lugar, la variable Turismo está determinada principalmente por la llegada de ciudadanos provenientes de los países de la Alianza al territorio costarricense en todas las vías. En este sentido, el gasto medio por persona (gmp) en dólares \$ de los turistas no residentes, según el ICT al año 2018 fue de 1104.8. Razón por la cual si se multiplica ese gasto medio por la cantidad de turistas provenientes de México, Chile, Colombia y Perú, estas cifras representan un gran importe en términos de beneficios para el sector turístico del país.

El componente turístico es un soporte del crecimiento económico del país, colocando a México, una vez más, en la posición más alta; Colombia, en el segundo; Chile de tercero y Perú en la posición más baja.

Siendo así, es observable la relación comercial existente con México, que como se mencionó anteriormente forma parte de los principales socios comerciales del país. El Fondo Monetario Internacional (FMI) destaca a México, integrante de la AP como uno de los principales socio comerciales de Costa Rica, que actualmente ocupa un $3 \%$ del destino de las exportaciones del país, como una de las economías de mercados emergentes y en desarrollo de Latinoamérica, después de Brasil.
A pesar de que históricamente las cifras de los determinantes de importancia económica han sido algo bajas, cada uno de los países miembros de la Alianza del Pacífico tiene amplias oportunidades con Costa Rica e inclusive se puede explotar aún más el comercio con todos estos países, mejorando la relación comercial existente.

\section{Conclusiones}

En la actualidad, la tendencia mundial va dirigida hacia la integración regional y formación de bloques que permite a sus países miembros tener una mejor articulación política y de integración para negociar mejores condiciones en el intercambio comercial. Esta faceta de liberación comercial mundial ha puesto sobre la mesa "mega acuerdos" interesantes para Costa Rica, uno de ellos es la Alianza del Pacífico.

Desde el 2012, se acepta a Costa Rica como estado observador junto con otros 59 países, Argentina, Salvador, Estados Unidos, Guatemala, Panamá, Uruguay son algunos de los países que destacan en el continente americano. Su papel como estado observador no le ha permitido obtener beneficios adicionales a los acuerdos bilaterales ya existentes con cada uno de los países miembros. Sin embargo, se plantean diversos oportunidades/beneficios en vista a su incorporación, entre ellos se encuentran: cero aranceles en el intercambio de bienes y servicios, atracción de flujos de inversión y turismo en mayores volúmenes, fomento del crecimiento económico y atacar el desempleo regional, cooperación, mayor movilización de personas, facilitación de becas para estudios en el extranjero, diversificación de las relaciones políticas y económicas con una visión dirigida a los países del Asia. Adicionalmente, otra razón importante sería la atracción y el desarrollo de tecnologías, para el 27 de septiembre del 2019 en el foro "El futuro del trabajo de la Alianza del Pacífico frente a los desafíos de la Cuarta Revolución Industrial" llevado a cabo en Nueva York, se pone en evidencia los esfuerzos que se realizan en la búsqueda por estrategias digitales, innovación ciencia y tecnología y promoción del crecimiento verde, todas estas iniciativas para alcanzar al 2030 una AP más integrada, conectada globalmente con un desarrollo más sostenible e inclusivo. 
Los principales determinantes de importancia económica para Costa Rica, provenientes de los países de la AP, son el componente de Inversión Extranjera Directa y el Turismo.

Como resultado México, país miembro de la AP, genera el mayor aporte económico de los miembros de la Alianza al país en ambas variables, por lo que Costa Rica podría ampliar la generación de nuevos nichos de mercado. En segundo lugar, se encuentra Colombia con aportes grandes de inversión al país y en menor medida Chile y Perú. El aporte turístico de igual manera, el mayor flujo de turistas proviene de México y Colombia, con un total de ingreso de 145,641 personas, al 2018.

Por otro lado, existen sectores que adversan o son partidarios de mantener y fortalecer la AP. Ante cualquier escenario, es necesario fortalecer el diálogo político y social, así como generar una agenda que fortalezca los sectores que podrían verse más afectados con la decisión.

El presente estudio abre la puerta para desarrollar múltiples líneas de investigación futuras, con el objetivo de cuantificar los posibles beneficios futuros y repercusiones económicas que traería consigo la incorporación de Costa Rica a la Alianza del Pacífico. Entre ellas, se encuentra ampliar la metodología utilizada para el cálculo del Índice de Importancia Económica para cada uno de los países miembros de la AP. Estudios que cuantifiquen otras variables económicas como el empleo, cooperación internacional, entrada de divisas y el impacto que podría generar. En esta misma línea, estudios que cuantifiquen las repercusiones que tendría para el país, el aumentar la relación comercial con los países del Asia.

\section{Bibliografía}

Arévalo, L. G. (2014). La Alianza Pacífico: geopolítica e integración económica. Revista Vía Iuris, 2014 ( $\left.{ }^{\circ} 16\right)$, pp. 159-172.

Banco Central de Chile. (2019). Base de datos estadísticos. Banco Central de Chile. https://siz.bcentral.cl/ siete/secure/cuadros/arboles.aspx
Banco Central de Costa Rica. (2019). Indicadores económicos. Banco Central de Costa Rica. https:// www.bccr.fi.cr/seccion-indicadores-economicos/ indicadores econ $\% \mathrm{C}_{3} \%$ B3micos.

Banco Central de México. (2019). Estadísticas e Indicadores. Banco Central de México. http:// www.anterior.banxico.org.mx/estadisticas/index. html

Banco de la República de Colombia.(2019). Estadísticas. Banco de la República de Colombia. http://www. banrep.gov.co/es/

Banco de la Reserva del Perú. (2019). Estadísticas económicas. Banco de la Reserva del Perú. http:// www.bcrp.gob.pe/estadisticas.html

Banco Mundial. (2016). Datos del Banco Mundial. Banco Mundial. http://data.worldbank.org/news/newcountry-classifications-2015.

Banco Mundial. (2017). Millones de personas en América Latina y el Caribe están a un desastre de regresar a la pobreza. Banco Mundial. http:// www.bancomundial.org/es/news/pressrelease/2017/11/28/millones-personas-americalatina-caribe-desastre-pobreza.

Banco Mundial. (2019). América Latina y el Caribe: Panorama general . Banco Mundial. https://www. bancomundial.org/es/region/lac/overview.

Centro de Información Turística de Colombia (2019). Estadisticas. Centro de Información Turística de Colombia. http://www.citur.gov.co/

Comercio Exterior de Costa Rica. (2019). Alianza del Pacífico. Comercio Exterior de Costa Rica. http:// www.comex.go.cr/tratados/alianza-pacifico/.

Comercio Exterior de Costa Rica. (2019). Tratados. Comercio Exterior de Costa Rica. https://www. comex.go.cr/Tratados. 
Comisión de Promoción del Perú para la Exportación y el Turismo (2019). Exportaciones. Comisión de Promoción del Perú para la Exportación y el Turismo. https://www.promperu.gob.pe/

Comisión Económica para América latina y el Caribe. (2018). Inversión Extranjera Directa en América Latina y el Caribe. Comisión Económica para América Latina y el Caribe. Disponible en: http:// www.iberglobal.com/files/2018/ide_la_cepal.pdf

Comisión Económica para América latina y el Caribe. (2018). Panorama Social 2018. Comisión Económica para América Latina y el Caribe. https://www.cepal.org/es/comunicados/lapobreza-america-latina-se-mantuvo-estable2017-pero-aumento-la-pobreza-extrema

Del Pacífico, A. (2012). Acuerdo marco de la Alianza del Pacífico. Alianza del Pacífico. https:// alianzapacifico. net.

Departamento Administrativo Nacional de Estadística (2019). Sistema estadístico Nacional. Departamento Administrativo Nacional de Estadística. https://www.dane.gov.co/

Dirección Nacional de Aduanas de Chile (2019). Estadísticas COMEX. Dirección Nacional de Aduanas de Chile. https://www.aduana.cl/direccion-nacional-deaduanas/aduana/2019-01-10/o92719.html

Fondo Monetario Internacional. Departamento de Secretaría. (2017). Informe Anual del FMI 2017: Promover el Crecimiento Inclusivo. Fondo Monetario Internacional. https://www.imf.org/ external/pubs/ft/ar/2017/eng/assets/languages/ IMF-AR17-Spanish.pdf

Fondo Monetario Internacional. (2019). Informe sobre la estabilidad financiera mundial (GFSR) de abril de 2019. Fondo Monetario Internacional. https://www.imf.org/es/Publications/GFSR/ Issues/2019/03/27/Global-Financial-StabilityReport-April-2019\#Cap\%C3\%ADtulo\%201
Fondo Monetario Internacional. (2019). Perspectivas de la economía mundial: Desaceleración del crecimiento, precaria recuperación y Políticas mundiales de abril 2019. Fondo Monetario Internacional. https://www.imf.org/es/ Publications/GFSR

Fonseca, R. (2012). Índice de Competitividad Territorial aplicado a los Cantones de Heredia. Revista Economía y sociedad, 42, 67-86. https://www. researchgate.net/publication/290393371_ INDICE_DE_COMPETITIVIDAD TERRITORIAL_APLICADO_A_LOS CANTONES_DE_HEREDIA

Fonseca, R.; Cascante, C. (2017). Mapeo de actores y perspectivas de la adhesión de Costa Rica a la OCDE y la Alianza del Pacífico. Estado de la Nación. Informe Estado de la Nación en Desarrollo Humano Sostenible 2017. https:// estadonacion.or.cr/files/biblioteca_virtual/o23/ Politicas/Cascante\&Fonseca_2017.pdf

Fonseca, R.; López, A. (2015). Promoción comercial focalizada: Pasos para elaborar una estrategia en Costa Rica. En Bermúdez, J; Otoya, M (Ed), Comercio, Tecnología e Innovación, Tomo I (pp. 143-185). https://www.researchgate.net/ publication/290394398_Promocion_comercial_ focalizada_-_Pasos_para_elaborar_una_ estrategia_en_Costa_Rica

Fonseca, R.; López, A. (2018). La ayuda al comercio y su relación con la competitividad internacional de los países menos adelantados. Economía y Sociedad, 23 (54), 1-24. http://www.revistas.una.ac.cr/ index.php/economia/article/view/10615/13166

Instituto Costarricence de Turismo. (2019). Anuario 2018. Instituto Costarricense de Turismo. https:// www.ict.go.cr/es/documentosinstitucionales/ estad\% $\% \mathrm{C}_{3} \% \mathrm{ADsticas} /$ informesestad\% $\% \mathrm{C}_{3} \% \mathrm{AD}$ sticos/anuarios/2005-2015/1349-2018-1/file.html. 
Mercado Común del Sur. (2018). Sistema de Estadísticas de Comercio Exterior del Mercosur. Mercado Común del Sur. https://www.mercosur.int/ sistema-de-estadisticas-de-comercio-exteriordel-mercosur/

Mora-Mora, J. U. (2016). La Alianza del Pacífico y Mercosur: evidencias de convergencia económica. Estudios Gerenciales, 32(141), 309-318. http://www. scielo.org.co/pdf/eg/v32n141/o123-5923eg-32-141-00309.pdf

Organización para la Cooperación y el Desarrollo Económico. (2019). Estadísticas. Organización para la Cooperación y el Desarrollo Económico. http://www.oecd.org/centrodemexico/ estadisticas/

Passport. (5 de octubre 2019). Economy, Finance and Trade: Statistics. Portal Euromonitor. Sistema de Información Documental de la Universidad Nacional. Costa Rica. http://www.portal. euromonitor.com.una.idm.oclc.org/portal/ magazine/index/?PageTypeId=2\&MenuCode $=273 \&$ PageId $=268 \&$ ImageUrl $=\% 2$ Ficons $\% 2 \mathrm{~F}$ economies $\% 2$ Feconomy $\% 2$ ofinance $\% 26$ trade _2opx_black-03.png\&Title=Economy,\%20 Finance\%20and\%2oTrade

Peñaranda, C. (2016). Disminuye la Inversión Extranjera Directa en países de la Alianza del Pacífico. Instituto de Economía y Desarrollo Empresarial de la Cámara de Comercio de Lima, Perú. https:// www.camaralima.org.pe/repositorioaps/o/o/par/ r766_2/informeeconomico_768.pdf

Promotora del Comercio Exterior. (2015). Estadísticas de Comercio Exterior 2015. Promotora de Comercio Exterior. https://procomer.com/downloads/ estudios/estudio_estadistico_2015/Anuario_ Estadistico_2015.pdf
Promotora del Comercio Exterior. (2019). Productos exportados de Costa Rica. Promotora de Comercio Exterior. https://www.procomer.com/ es/comprar-productos-exportadores-costa-rica

Reina, M. (2016). Impacto económico de la Inversión Extranjera Directa en Colombia 2007-2015. Centro de Investigación Económica y Social. https://repository.fedesarrollo.org.co/bitstream/ handle/11445/3336/Repor_Septiembre_2016_ Reina_et_al.pdf?sequence $=2 \&$ isAllowed $=\mathrm{y}$

Ulloa, A. (2018). Temas de diálogo y acción regional: Minería en los países de la Alianza del Pacífico. Banco Interamericano de Desarrollo. http:// dx.doi.org/10.18235/0001007. 